\title{
A PROSPECTIVE NON-RANDOMISED TRIAL TO COMPARE THE RESULTS OF INTRAOCULAR PRESSURE REDUCTION BETWEEN TRABECULECTOMY AND DEEP SCLERECTOMY IN PRIMARY OPEN ANGLE GLAUCOMA
}

\author{
Natarajan Parvathasundari', Subbiahvasan Chandrakumar'2, Sukumaran Kochammal Sowmi', \\ Natarajarathinam Sudhapriyadharsini ${ }^{4}$, Palanisamy Menaka ${ }^{5}$, Abdullah Haroon Shaminabegum ${ }^{6}$, Jeyaprakash Jeyakumari ${ }^{7}$
}

\begin{abstract}
${ }^{1}$ Associate Professor, Department of Ophthalmology, Madurai Medical College.
2Professor, Department of Ophthalmology, Madurai Medical College.

${ }_{3}^{3}$ Senior Resident, Department of Ophthalmology, Madurai Medical College.

4Junior Resident, Department of Ophthalmology, Madurai Medical College.

5 Senior Resident, Department of Ophthalmology, Madurai Medical College.

6Junior Resident, Department of Ophthalmology, Madurai Medical College.

7Junior Resident, Department of Ophthalmology, Madurai Medical College.
\end{abstract}

\section{BACKGROUND}

ABSTRACT

Maintenance of Intraocular Pressure and its pathophysiology revolves around the aqueous dynamics, and this is almost always the cause of Primary Open Angle Glaucoma and thus becoming the target for many medical and surgical therapies. Deep sclerectomy still holds an equal place in management. As in deep sclerectomy there is non-invasion of the anterior chamber, the reduced postoperative complications like over filtration and hypotony are rare.

Aims and Objectives- To evaluate and compare the results of trabeculectomy and deep sclerectomy in mild and moderate primary open angle glaucoma patients and assess their intraocular pressure pre-operatively and post-operatively.

\section{MATERIALS AND METHODS}

This was a prospective randomised trial conducted among 50 patients with mild or moderate primary open angle glaucoma at Government Rajaji Hospital for a period of nine months. All subjects were evaluated pre-operatively and randomly divided into 2 groups using simple randomisation method. IOP was measured on the $3^{\text {rd }}$ post-operative day followed by weekly intervals for 1 month and monthly intervals thereafter till 6 months.

\section{RESULTS}

Male-to-female ratio was almost equal in both groups. There was significant reduction of IOP post-operatively in the trabeculectomy as well as the deep sclerectomy groups, right from the $3^{\text {rd }}$ post-operative day till the $6^{\text {th }}$ month. The advantages of deep sclerectomy over trabeculectomy in open angle glaucoma are safety without loss of efficacy with fewer complications and faster recovery. However, the long-term efficacy of IOP control in deep sclerectomy is poor, unlike in trabeculectomy, in which case a number of adjunctive techniques are being used to increase the efficacy like intraoperative use of antimetabolites, Ologen like intrascleral implants as well as performing laser goniopuncture early when the IOP rises above the target value.

\section{CONCLUSION}

Deep sclerectomy were equally effective in reducing the intraocular pressure in POAG patients during the immediate postoperative and up to 6 months of follow-up period. Deep sclerectomy henceforth should be considered at an earlier stage.

\section{KEYWORDS}

Intraocular Pressure, Open Angle Glaucoma, Trabeculectomy, Anti-Glaucoma Surgery.

HOW TO CITE THIS ARTICLE: Parvathasundari N, Chandrakumar S, Sowmi SK, et al. A prospective non-randomised trial to compare the results of intraocular pressure reduction between trabeculectomy and deep sclerectomy in primary open angle glaucoma. J. Evolution Med. Dent. Sci. 2018;7(05):623-625, DOI: 10.14260/jemds/2018/141

\section{BACKGROUND}

Glaucoma is a multifactorial optic neuropathy ${ }^{1}$ causing damage to retinal ganglion cells at levels beyond normal baseline age related loss, resulting in a form of optic atrophy with intraocular pressure as a major modifiable factor in this

'Financial or Other Competing Interest': None.

Submission 02-12-2017, Peer Review 12-01-2018,

Acceptance 18-01-2018, Published 29-01-2018.

Corresponding Author:

Dr. Natarajan Parvathasundari,

Associate Professor of Ophthalmology,

Eye Department OP No. 50,

Govt. Rajaji Hospital, No. 1,

Panagal Road, Madurai-625020, Tamilnadu.

E-mail: eyedeptgrh@gmail.com

DOI: $10.14260 /$ jemds $/ 2018 / 141$

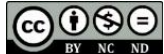

progressive disease. Aqueous is secreted by the ciliary body in the posterior chamber and reaches the anterior chamber via pupil, from where it is drained through the angle of the anterior chamber. Maintenance of Intraocular Pressure (IOP) and its pathophysiology revolves around the aqueous dynamics, ${ }^{2}$ and this is almost always the cause of Primary Open Angle Glaucoma (POAG) and thus becoming the target for many medical and surgical therapies. Though trabeculectomy has stood the test of time with its inherent advantages over many other surgical procedures, deep sclerectomy still holds an equal place in management. As in deep sclerectomy there is non-invasion of the anterior chamber, the reduced post-operative complications like over filtration and hypotony are rare. ${ }^{3}$ But deep sclerectomy is done rarely due to its difficult learning curve. In our study, we thus compared the efficacy of both the procedures in terms of 
post-operative intraocular pressure reduction in patients with POAG.

\section{Aims and Objectives}

To evaluate and compare the results of trabeculectomy and deep sclerectomy in mild and moderate primary open angle glaucoma patients and assess the intraocular pressure preoperatively and post-operatively in them.

\section{MATERIALS AND METHODS}

This was a prospective non-randomised trial conducted among 50 patients with mild or moderate primary open angle glaucoma at Department of Ophthalmology, Government Rajaji Hospital, Madurai for a period of nine months. The patients who were above 40 years of age with clinical and perimetric evidence of POAG, intraocular pressure over 21 mmHg even after Maximum Medical Therapy (MTMT) and with no previous history of ocular surgery were included in our study. Patients less than 40 years of age, angle closure glaucoma, ocular surface disorder, conjunctival injuries, systemic contraindications for surgery, severe POAG with gross visual field defects and not consenting for study were excluded. The sample size of 50 is calculated based on the mean (std. deviation) of difference in change in the IOP from baseline to 6 months in the Deep Sclerectomy group and Trabeculectomy group, i.e. 12.7 (4.2) and 14.5 (5.1) with 95\% confidence interval using the formula $\mathrm{n}=\mathrm{Z}^{2}{ }_{(1-\alpha / 2)}\left[2 \mathrm{~S}^{2} \mathrm{P}\right] / \mathrm{d}^{2}$ and $\mathrm{S}^{2} \mathrm{P}=\left[\mathrm{S}_{1}{ }^{2}+\mathrm{S}_{2}{ }^{2}\right] / 2$ where $\mathrm{S}_{1}{ }^{2}$ and $\mathrm{S}_{2}{ }^{2}$ is the standard deviation of first and second groups, $\mathrm{S}_{\mathrm{P}}{ }^{2}$ is pooled standard deviation, $\mathrm{d}$ is precision and $\alpha$ is significance level. ${ }^{4}$

All subjects were evaluated pre-operatively; detailed history, slit lamp examination, visual acuity, intraocular pressure (IOP), Goldmann 3-mirror gonioscopy, visual fields by Standard Humphrey's automated perimetry, colour vision by Ishihara's chart and fundus examination with slit lamp bio-microscopy using +78 D lens. Randomisation was determined just before surgery. Patients were randomly assigned based on a surgical chart number to receive either conventional trabeculectomy (patients with even numbers) or deep sclerectomy (patients with odd numbers). Patients were thoroughly informed about the two procedures and written informed consent was obtained. The subjects under Group A underwent conventional trabeculectomy, while under Group B underwent deep sclerectomy. IOP was measured on the $3^{\text {rd }}$ post-operative day followed by weekly intervals for 1 month and monthly intervals thereafter till 6 months. All the findings were recorded in the master chart and were subjected to statistical analysis.

All the statistical analysis was done using statistical software IBM SPSS Ver. 21.0 (Armonk, NY). Mean (standard deviation), Frequency (percentages) were calculated. Unpaired Student's test was used to compare the IOP at each time point between the two groups. Repeated measures ANOVA test was used to compare the IOP at repeated time points in each group. The $\mathrm{P}$ value $<0.05$ was taken to denote significant relationship.

\section{RESULTS}

In our study among the 50 subjects divided into 2 groups, containing 25 subjects each, the mean age of the subjects in the trabeculectomy was 57 years and in the deep sclerectomy group was 55 years. Male-to-female ratio was almost equal in both groups. There was a statistically significant reduction of IOP post-operatively in the trabeculectomy as well as the deep sclerectomy groups, right from the $3^{\text {rd }}$ post-operative day till the $6^{\text {th }}$ month. Though there was a statistically significant difference in the reduced IOP during the first postoperative week between the 2 groups (trabeculectomy group having the lower IOP). There was no statistically significant difference between the groups in the subsequent weeks till the $6^{\text {th }}$ month.

The repeated measures ANOVA test is used to compare the IOP measured at different time points in each group and it was found statistically significant $(\mathrm{p}<0.001)$ in Table 1 , which says that there is a difference in the IOP measurements at each follow-up in both the groups. The post-hoc test called Bonferroni is used to compare the pre-op IOP with the IOP measured at Day 3, 7, 14, 21 and 28 and also in $2^{\text {nd }}, 3^{\text {rd }}, 4^{\text {th }}$ and $5^{\text {th }}$ month respectively for both Deep Sclerectomy and Trabeculectomy group. The $\mathrm{P}$ values are $<0.001$ in Table 2 , which is statistically significant. It interprets that there is a difference in the pre-op IOP and IOP measured at follow-up periods.

\begin{tabular}{|c|c|c|c|c|c|c|c|}
\hline \multirow{2}{*}{\begin{tabular}{|c|} 
Timing for \\
IOP \\
Measure \\
ment \\
\end{tabular}} & \multicolumn{3}{|c|}{ Deep Sclerectomy } & \multicolumn{3}{|c|}{ Trabeculectomy } & \multirow[b]{2}{*}{$\begin{array}{c}P \\
\text { value }^{T}\end{array}$} \\
\hline & $\mathbf{n}$ & $\begin{array}{c}\text { Mean } \\
\text { (SD) }\end{array}$ & $\begin{array}{l}\text { Min - } \\
\text { Max }\end{array}$ & $\mathbf{n}$ & $\begin{array}{c}\text { Mean } \\
\text { (SD) }\end{array}$ & $\begin{array}{c}\text { Min - } \\
\operatorname{Max}\end{array}$ & \\
\hline Pre-op & 25 & & & 25 & & & 0.825 \\
\hline Day 3 & 25 & & $\begin{array}{c}11.5- \\
19.0 \\
\end{array}$ & 25 & & $\begin{array}{c}12.0- \\
17.0 \\
\end{array}$ & 0.002 \\
\hline Day & 25 & $\begin{array}{l}14.92 \\
(2.06)\end{array}$ & $\begin{array}{c}11.0- \\
19.0 \\
\end{array}$ & 25 & & $\begin{array}{c}12.0- \\
16.0 \\
\end{array}$ & .005 \\
\hline Day 14 & 25 & $\begin{array}{l}14.48 \\
(1.70)\end{array}$ & $\begin{array}{c}11.0- \\
17.0 \\
\end{array}$ & 25 & & $\begin{array}{c}12.0- \\
16.0 \\
\end{array}$ & 0.017 \\
\hline Day 21 & 25 & & $\begin{array}{c}11.0- \\
17.0 \\
\end{array}$ & 25 & & $\begin{array}{c}12.5- \\
15.5 \\
\end{array}$ & 0.062 \\
\hline $\mathrm{D}$ & 25 & & $\begin{array}{c}11.0- \\
17.0 \\
\end{array}$ & 25 & & $\begin{array}{c}12.5- \\
15.5 \\
\end{array}$ & 0.192 \\
\hline onth & 25 & $\begin{array}{l}13.74 \\
(1.37) \\
\end{array}$ & $\begin{array}{c}11.0- \\
17.0 \\
\end{array}$ & 25 & $\begin{array}{l}13.62 \\
(1.10)\end{array}$ & $\begin{array}{c}12.0- \\
16.0 \\
\end{array}$ & 0.734 \\
\hline th & 25 & $\begin{array}{l}13.76 \\
(1.45)\end{array}$ & $\begin{array}{c}11.0- \\
17.0\end{array}$ & 25 & $\begin{array}{l}13.34 \\
(0.85)\end{array}$ & $\begin{array}{c}12.0- \\
16.0 \\
\end{array}$ & 0.218 \\
\hline nth & 25 & $\begin{array}{l}13.50 \\
(1.38)\end{array}$ & $\begin{array}{c}11.0- \\
16.5 \\
\end{array}$ & 25 & $\begin{array}{c}13.18 \\
(0.80)\end{array}$ & $\begin{array}{c}12.0- \\
15.5 \\
\end{array}$ & 0.320 \\
\hline th & 25 & $\begin{array}{l}13.44 \\
(1.38)\end{array}$ & $\begin{array}{c}11.0- \\
16.0 \\
\end{array}$ & 25 & $\begin{array}{l}12.98 \\
(0.81)\end{array}$ & $\begin{array}{c}11.5- \\
14.5 \\
\end{array}$ & 0.157 \\
\hline P value ${ }^{R}$ & \multicolumn{3}{|c|}{$<0.001$} & \multicolumn{3}{|c|}{$<0.001$} & 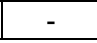 \\
\hline & & & & & & & \\
\hline
\end{tabular}

T- unpaired ' $\mathrm{t}$ ' test and R- Repeated measures of ANOVA.

\begin{tabular}{|c|c|c|}
\hline $\begin{array}{c}\text { Comparison of IOP } \\
\text { at different } \\
\text { Time Points }\end{array}$ & $\begin{array}{c}\text { Deep } \\
\text { Sclerectomy } \\
\text { P value }^{\mathrm{B}}\end{array}$ & $\begin{array}{c}\text { Trabeculectomy } \\
\text { P value }^{\mathrm{B}}\end{array}$ \\
\hline Pre OP Vs. Day 3 & $<0.001$ & $<0.001$ \\
\hline Pre OP Vs. Day 7 & $<0.001$ & $<0.001$ \\
\hline Pre OP Vs. Day 14 & $<0.001$ & $<0.001$ \\
\hline Pre OP Vs. Day 21 & $<0.001$ & $<0.001$ \\
\hline Pre OP Vs. Day 28 & $<0.001$ & $<0.001$ \\
\hline Pre OP Vs. 2nd Month & $<0.001$ & $<0.001$ \\
\hline Pre OP Vs. 3rd Month & $<0.001$ & $<0.001$ \\
\hline Pre OP Vs. 4th Month & $<0.001$ & $<0.001$ \\
\hline Pre OP Vs. 5th Month & $<0.001$ & $<0.001$ \\
\hline \multicolumn{2}{|c|}{ Table 2. Comparison of IOP at different Time Points } \\
\hline \multicolumn{2}{|c|}{ between the Two Groups } \\
\hline
\end{tabular}

B- Bonferroni Test 


\section{DISCUSSION}

The decision to perform Glaucoma surgery depends on the individual patient with factors including the degree of visual impairment, target IOP, stage of glaucoma, compliance, age, life expectancy and other systemic illnesses. Trabeculectomy, in use since the mid 1960's is the most effective glaucoma surgery in terms of IOP reduction, but carries its own limitations. More recently, non-penetrating procedures as deep sclerectomy with or without an intrascleral implant as well as viscocanalostomy have been developed as alternatives to trabeculectomy with lesser rate of complications. The major advantage of deep sclerectomy is that it prevents sudden hypotony encountered during and after trabeculectomy, as it allows a progressive filtration of aqueous humour through the thin remaining TrabeculoDescemet's Membrane (TDM) into intrascleral reservoir. 5 Complication rates were significantly lower with deep sclerectomy, as it is a non-penetrating surgery and there is no requirement of peripheral iridectomy which provokes inflammation like in trabeculectomy. In our study, the IOP reduction in POAG patients was comparable and there exists no statistically significant difference between the two.

Studies done by Cillino et al $^{6}$ also concluded that nonpenetrating deep sclerectomy and trabeculectomy without enhancements control IOP efficaciously after a 2-year followup. But when a lower target IOP and probability of success over time are considered, trabeculectomy exhibits a better trend and could therefore be more suitable for a higher promising level for longer life expectancy. Khairy et $\mathrm{al}^{7}$ also confirmed that deep sclerectomy reduced the IOP temporarily, while minimising the risk of post-operative complications commonly encountered with standard trabeculectomy. However, after a 36-month follow-up, the surgery failed to maintain a low pressure with success rate at 30 months being $18.9 \%$.

The advantages of deep sclerectomy over trabeculectomy in open angle glaucoma are safety without loss of efficacy with fewer complications and faster recovery. However, the long-term efficacy of IOP control in deep sclerectomy is poor, unlike in trabeculectomy, in which case a number of adjunctive techniques are being used to increase the efficacy like intraoperative use of antimetabolites, Ologen like intrascleral implants ${ }^{8}$ as well as performing laser goniopuncture early when the IOP rises above the target value. The main disadvantage of deep sclerectomy is that, it is a technically challenging procedure with long learning curve.
The most common intraoperative complication is TDM perforation, which essentially converts deep sclerectomy to a trabeculectomy.

\section{CONCLUSION}

Both trabeculectomy and deep sclerectomy were equally effective in reducing the intraocular pressure in Primary Open Angle Glaucoma patients during the immediate postoperative and upto 6 months of follow-up period. Deep sclerectomy in management of POAG appears to have a superior safety profile than penetrating procedures, henceforth should be considered at an earlier stage, especially in cases of intolerance or non-availability of medical laser therapy.

\section{REFERENCES}

[1] Halpern DL, Grosskreutz CL. Glaucomatous optic neuropathy: mechanisms of disease. Ophthalmol Clin North Am 2002;15(1):61-8.

[2] Goel M, Picciani RG, Lee RK, et al. Aqueous humor dynamics: a review. Open Ophthalmol J 2010;4:52-9.

[3] Varga A, Shaarawy T. Deep sclerectomy: safety and efficacy. Middle East Afr J Ophthalmol 2009;16(3):123-6.

[4] El Sayyad F, Helal M, El-Kholify H, et al. Nonpenetrating deep sclerectomy versus trabeculectomy in bilateral primary open-angle glaucoma. Ophthalmology 2000;107(9):1671-4.

[5] Sanseau AC, Argento C, Badoza D. Nonpenetrating deep sclerectomy is gaining popularity among physicians. Ocular Surgery News Europe/Asia-Pacific Edition (Archive), April 2000.

[6] Cillino S, Di Pace F, Casuccio A, et al. Deep sclerectomy versus punch trabeculectomy with or without phacoemulsification: a randomised clinical trial. J Glaucoma 2004;13(6):500-6.

[7] Khairy HA, Green FD, Nassar MK, et al. Control of intraocular pressure after deep sclerectomy. Eye (Lond) 2006;20(3):336-40.

[8] Ambresin A, Shaarawy T, Mermoud A. Deep sclerectomy with collagen implant in one eye compared with trabeculectomy in the other eye of the same patient. J Glaucoma 2002;11(3):214-20. 